x C. J. L. \& Turner, G. (1977a). Can. J. Chem. 55, Sergienko, V. S., Poral-Koshits, M. A. \& Khodaskova, :32-339.

ia. J. L. L. Turner. G. (1977b). Can. J. Chem. In the T. S. (1974). J. Struct. Chem. 15, 250-255.

mass.

.MHNN, R. K. \& SCHLEMPER. E. O. (1971). Inorg. Chem. 11. $2352-2354$

Shandes, R., Schlemper, E. O. \& Murmann, R. K. (1971). Inorg. Chem. 10, 2785-2789.

TURner, G. (1976). PhD Thesis. McMaster Univ.. Hamilton. Ontario, Canada.

${ }_{3}$ Cryst. (1978). B34, 927-930

\title{
Sodium 5,6-Dihydro-2-thiouracil-6-sulfonate Monohydrate
}

\author{
By N. B. Jain, Byungkook Lee, ${ }^{*}$ Kristin Bowman Mertes and Ian H. Pitman \\ yartments of Pharmaceutical Chemistrv and Chemistry, The University of Kansas, Lawrence, Kansas 66045, \\ USA
}

(Received 8 July 1977; accepted 28 October 1977)

stltact. $\mathrm{C}_{4} \mathrm{H}_{7} \mathrm{~N}_{2} \mathrm{O}_{5} \mathrm{~S}, \mathrm{Na}$, monoclinic, $P 2_{1} / c, Z=4, a$ 13.101 (4), $b=7.043$ (3), $c=9.654$ (5) $\AA, \beta=$ $98(4)^{\circ}, D=1.90(1), D_{c}=1.90 \mathrm{~g} \mathrm{~cm}^{-3}, \lambda(\mathrm{Mo}$ $l=0.7107 \AA, R=0.033$ for 2045 observed stions. This is the product of a bisulfite addition ation of 2 -thiouracil at $\mathrm{pH} 8$. The sulfonate group is od attached axially at the 6-position of the aracil.

soduction. The title compound was prepared by stion of bisulfite ion to 2-thiouracil. Preliminary uession photographs of the crystals obtained from tous solution showed monoclinic symmetry and tiction patterns ( $0 k 0$ reflections absent when $k$ odd, reflections absent when $l$ odd) consistent with the se group $P 2_{1} / c$. The calculated density for $Z=4$ sid with the experimental density obtained by tion in a monobromoethane-chloroform mixture. small crystal $(0.4 \times 0.2 \times 0.2 \mathrm{~mm})$ was then anted on a Syntex $P 2$ diffractometer. Accurate cell insions were determined from a least-squares fit of

$\omega, \varphi$ and $\chi$ for 15 reflections with graphite-mono-

Umated Mo $K r$ radiation $(\lambda=0.71069 \AA)$. Data

?ecollected with a $\theta-2 \theta$ scan technique, the details of

have been reported (Seccombe, Lee \& Henry,

ij. 2642 reflections were measured with $2 \theta \leq 60^{\circ}$

which 2045 had $I>3 \sigma(I)$ and were used for data

His. The data were then corrected for the $1.8 \%$

ay that was observed, and reduced to the structure

or amplitudes by the application of the Lorentz-

arization correction. Because of the small linear

orption coefficient, $3.39 \mathrm{~cm}^{-1}$, and the small size of

crystal, no absorption or extinction correction was
ind

"Aut ior to whom correspondence should be addressed.

The positions of the $\mathrm{S}$ and $\mathrm{Na}$ atoms were found from a Patterson map. All other atoms, including $\mathrm{H}$, were found in subsequent electron density and dif ference electron density maps. For the refinement, all non-hydrogen atoms were treated with anisotropic thermal parameters and all $\mathrm{H}$ atoms with fixed isotropic thermal parameters. The final discrepancy indices were $R_{1}=\Sigma|| F_{0}|-| F_{c}|| / \Sigma\left|F_{0}\right|=0.033$ and $R_{2}=\mid \Sigma w\left(\left|F_{0}\right|\right.$ $\left.\left.-\left|F_{c}\right|\right)^{2} / \Sigma w\left|F_{o}\right|^{2}\right\}^{1 / 2}=0.042$

The positional and isotropic thermal parameters are given in Table 1 with their estimated standard

Table 1. Positional $\left(\times 10^{3} ;\right.$ for $\left.\mathrm{H} \times 10^{3}\right)$ and isotropic thermal $\left(\AA^{2}\right)$ parameters with e.s.d.'s in parentheses

\begin{tabular}{lcccc} 
& \multicolumn{1}{c}{$y$} & $z$ & $B$ \\
$\mathrm{~S}(1)$ & $15760(4)$ & $73961(8)$ & $11856(6)$ & $1.24(6)$ \\
$\mathrm{S}(2)$ & $35651(4)$ & $23543(7)$ & $-4964(5)$ & $1.93(5)$ \\
$\mathrm{Na}$ & $49649(7)$ & $1112(11)$ & $25919(9)$ & $1.94(9)$ \\
$\mathrm{O}(1)$ & $36431(12)$ & $5781(22)$ & $-12501(16)$ & $1.72(17)$ \\
$\mathrm{O}(2)$ & $43941(11)$ & $25652(21)$ & $7689(14)$ & $2.13(15)$ \\
$\mathrm{O}(3)$ & $34528(12)$ & $39906(23)$ & $-14219(16)$ & $2.35(17)$ \\
$\mathrm{O}(4)$ & $4164(12)$ & $32891(25)$ & $-29360(15)$ & $2.24(18)$ \\
$\mathrm{O}(w)$ & $40357(13)$ & $76443(25)$ & $12326(17)$ & $1.50(18)$ \\
$\mathrm{N}(1)$ & $22447(13)$ & $39237(26)$ & $9063(17)$ & $1.84(18)$ \\
$\mathrm{N}(3)$ & $10175(14)$ & $50569(27)$ & $-9873(18)$ & $1.34(19)$ \\
$\mathrm{C}(2)$ & $16249(15)$ & $53378(29)$ & $3377(21)$ & $1.47(20)$ \\
$\mathrm{C}(4)$ & $9205(15)$ & $33624(31)$ & $-17239(20)$ & $1.57(21)$ \\
$\mathrm{C}(5)$ & $14085(16)$ & $16806(30)$ & $-9085(22)$ & $1.58(21)$ \\
$\mathrm{C}(6)$ & $23815(16)$ & $21612(29)$ & $1978(20)$ & $2.08(19)$ \\
$\mathrm{H}(1 w, 1)$ & $341(3)$ & $763(5)$ & $115(4)$ & 3.29 \\
$\mathrm{H}(11,2)$ & $408(3)$ & $774(5)$ & $48(4)$ & 3.29 \\
$\mathrm{H}(1)$ & $258(3)$ & $414(5)$ & $163(3)$ & 2.12 \\
$\mathrm{H}(2)$ & $63(3)$ & $609(5)$ & $-136(3)$ & 2.85 \\
$\mathrm{H}(5,1)$ & $87(3)$ & $137(5)$ & $-43(3)$ & 2.34 \\
$\mathrm{H}(5,2)$ & $154(3)$ & $72(4)$ & $-154(3)$ & 2.34 \\
$\mathrm{H}(6)$ & $251(2)$ & $112(5)$ & $89(3)$ & 2.06
\end{tabular}




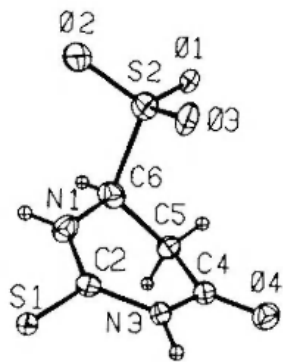

Fig. 1. Stercoview of DHTUS anion. The $50 \%$ probability thermal cllipsoids are shown for non-hydrogen atoms.

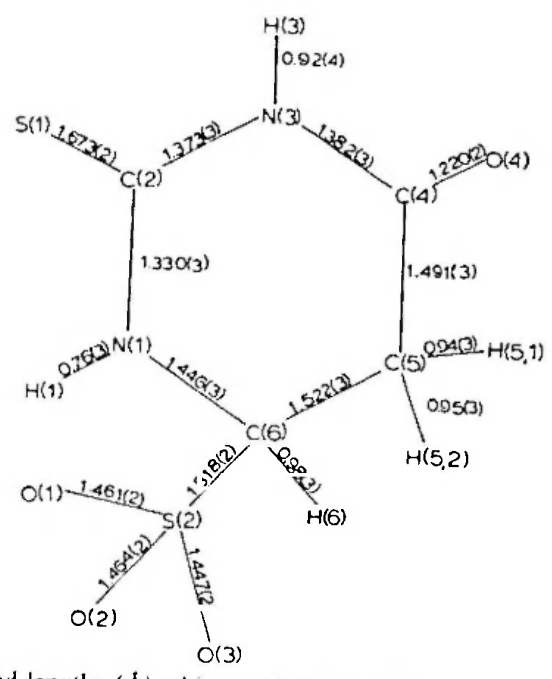

Fig. 2. Bond lengths $(A)$ with e.s.d.'s in parentheses; not shown on the tigure: $O($ in $)-H(w, 1) 0.81(4) . O(n)-H(w, 2) 0.74(4)$.

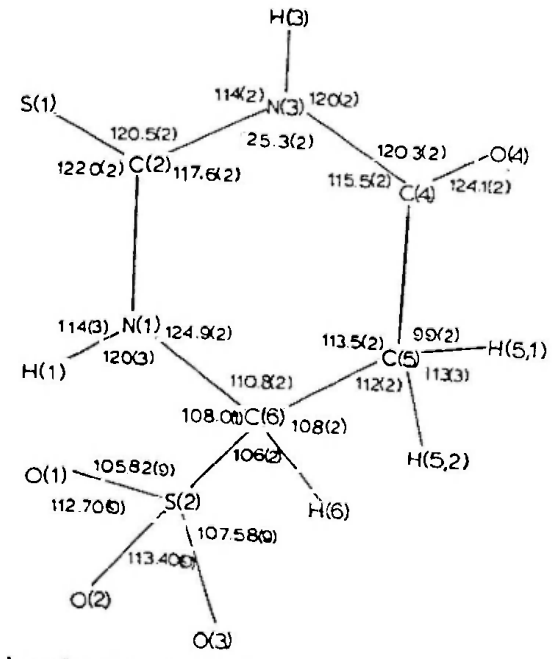

Fig. 3. Bond angles $\left(^{\circ}\right)$ with

the figure: $O(1)-S(2)-O(3)$. $n$ parentheses; not shown on 104.0 (1). $C(5)-C(6)-S(2) \quad 112.5(1), \quad O(2)-S(2)-C(6)$ $110(2) . \quad H(5.1)-C(5)-C(6) \quad 114.4(1), \quad H(6)-C(6)-N(1)$ $110(2), H(n, 1)-O(n)-H(n, 2) \quad 108(2), \quad H(5,2)-C(5)-C(4)$ deviations.* A stereodrawing of the molecule and it: atom numbering scheme are shown in Fig. 1 and the bond lengths and angles are given in Figs. 2 and 3.

Discussion. The common bisulfite ion modifies nuclei acid bases such as uracil under mild conditions (roon temperature and neutral $\mathrm{pH}$ ):

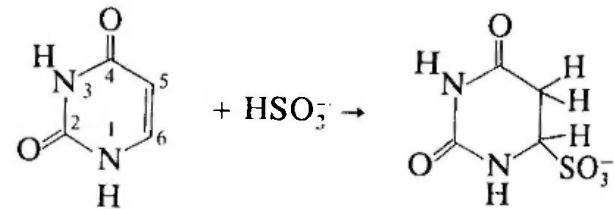

(I)

The product of this reaction has been identified and characterized by means of various spectroscopic techniques (Shapiro, Servis \& Welcher, 1970). The title compound was obtained by a similar reaction of 2 . thiouracil. The elemental analysis and its IR and NMR spectra are consistent with the expected structure but its UV spectrum shows a large absorbance $(\log \varepsilon=$ $4.14)$ at $\lambda-274 \mathrm{~nm}$. This was unexpected since (II) shows only end absorption at this wavelength. The structure shown in Fig. 1, however, clearly shows that the reaction went as expected. A pparently, the shift in the UV absorption spectrum is caused by the substitution of $S$ for $O$ at position 2.

The structure of the anion (DHTUS) is in general similar to that of the 5,6-dihydro-2-thiouracil molecule (DHTU) (Kojić-Prodić, Ružić-Toroš \& Coffou, 1976) except, of course, that one $\mathrm{H}$ at the 6-position is replaced by a sulfonate group. The differences in bond lengths and angles in these two structures are mostly minor with one notable exception: the $C(5)-C(6)$ bond length of 1.522 (3) $\AA$ in DHTUS is much closer to the

* Lists of structure factors and anisotropic thermal parameters nave been deposited with the British Library Lending Division as supplementary Publication No. SUP 33138 (14 pp.). Copies ma! be obtained through The Executive Secretary, International Union of Crystallography, 13 White Friars, Chester CHI INZ, England.

\section{Table 2. Dihedral angles $\left(^{\circ}\right)$}

The positive sense of rotation is clockwise while looking alore the $B C$ bond.

$\begin{array}{crr}A-B-C-D & \text { DHTUS } & \text { DHTU } \\ \mathrm{C}(6)-\mathrm{N}(1)-\mathrm{C}(2)-\mathrm{N}(3) & -4.5(3) & -7.4(4) \\ \mathrm{N}(1)-\mathrm{C}(2)-\mathrm{N}(3)-\mathrm{C}(4) & -6.6(3) & -5.2(4) \\ \mathrm{C}(2)-\mathrm{N}(3)-\mathrm{C}(4)-\mathrm{C}(5) & -8.6(3) & -5.6(4) \\ \mathrm{N}(3)-\mathrm{C}(4)-\mathrm{C}(5)-\mathrm{C}(6) & 32.3(2) & 27.4(4) \\ \mathrm{C}(4)-\mathrm{C}(5)-\mathrm{C}(6)-\mathrm{N}(1) & -40.1(2) & -36.9(4) \\ \mathrm{C}(5)-\mathrm{C}(6)-\mathrm{N}(1)-\mathrm{C}(2) & 27.9(2) & 28.6(4)\end{array}$


mal $\mathrm{C}-\mathrm{C}$ single bond length than the correading bond length of 1.474 (5) $\AA$ in DHTU. A less arkable difference that may be noted is a slight sing of about $1^{\circ}$ of each of the ring bond angles at :) and $\mathrm{C}(6)$.

The six-membered ring is puckered in both strucs. The ring in DHTUS is, however, somewhat more kered than that in DHTU. The following may be as evidence for this conclusion. (1) The sum of $\therefore$ dihedral angles within the ring is greater for ITUS $\left(120^{\circ}\right)$ than for DHTU $\left(111^{\circ}\right)$ (Table 2). (2) sum of the ring bond angles is less for DHTUS $\left.176^{\circ}\right)$ as compared with DHTU $\left(709 \cdot 7^{\circ}\right)$. (3) The is. displacement of the atoms N(1), C(2), N(3), and I) from their mean plane is greater for DHTUS than DHTU as discussed below.

hath structures the six-membered ring is puckered i such a manner that the four atoms $N(1), C(2), N(3)$,

$1 C(4)$ lie closely on one plane but the atoms $C(5)$

$\therefore C(6)$ are substantially displaced from this plane on

Table 3. Na ion interactions

Distances are in $\AA$, angles in degrees.

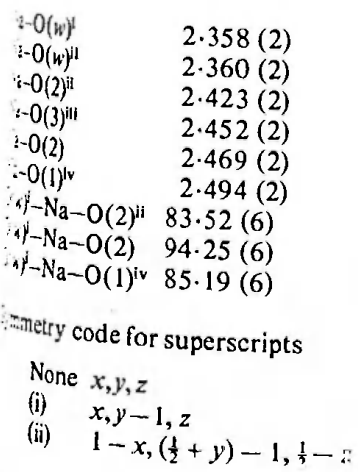

$\mathrm{O}(w)^{1}-\mathrm{Na}-\mathrm{O}(3)^{\mathrm{u} \prime} \quad 92 \cdot 34(6)$ $\mathrm{O}(w)^{\mathrm{i}}-\mathrm{Na}-\mathrm{O}(2)^{\mathrm{ii}} \quad 99.38(6)$ $\mathrm{O}(w)^{\mathrm{i}}-\mathrm{Na}-\mathrm{O}(2) \quad 82.49(6)$ $\mathrm{O}(w)^{\mathrm{i} i}-\mathrm{Na}-\mathrm{O}(1)^{\mathrm{iv}} \quad 90.25(6)$ $\mathrm{O}(w)^{\mathrm{ii}}-\mathrm{Na}-\mathrm{O}(3)^{\mathrm{iih}} \quad 91.75(6)$ $\mathrm{O}(2)^{\mathrm{i}}-\mathrm{Na}-\mathrm{O}(1)^{\mathrm{iv}} \quad 90.20(6)$ $\mathrm{O}(2)^{\mathrm{ii}}-\mathrm{Na}-\mathrm{O}(3)^{\mathrm{iii}} \quad 97.80(6)$ $\mathrm{O}(2)-\mathrm{Na}-\mathrm{O}(3)^{\mathrm{III}} \quad 86.94(6)$ $\mathrm{O}(2)-\mathrm{Na}-\mathrm{O}(1)^{\mathrm{iv}} \quad 84.95(6)$

(iii) $x, \frac{1}{2}-y, \frac{1}{2}+z$

(iv) $1-x,-y,-z$

either side (the 'pseudo-chair' form). The r.m.s. deviation of $N(1), C(2), N(3)$, and $C(4)$ from their least-square-displacement plane is $0.021 \dot{A}$ in DHTUS as compared with $0.016 \AA$ in DHTU. The two structures are substantially different in the manner in which the atoms $C(5)$ and $C(6)$ are displaced from this plane. In DHTU these two atoms are about equally displaced from the plane, with out-of-plane displacements of 0.226 and $0.238 \AA$ respectively for $\mathrm{C}(5)$ and $\mathrm{C}(6)$. In DHTUS, however, $C(5)$ is much more displaced than $C(6)$ since the corresponding distances are 0.323 and $0.198 \AA$, respectively. This trend is also reflected in the values of the dihedral angles $\mathrm{N}(3)-\mathrm{C}(4)-\mathrm{C}(5)-\mathrm{C}(6)$ and $C(2)-N(1)-C(6)-C(5)$. Since $N(1), C(2), N(3)$ and $C(4)$ lie nearly on one plane, these two dihedral angles essentially define the conformation of the ring. They are nearly equal in DHTU, but in DHTUS the former is substantially larger than the latter (Table 2).

The sulfonate group is attached to the ring axially. The dihedral angle around the $C(6)-S(2)$ bond is such that the three sulfonate $\mathrm{O}$ atoms are nearly staggered with respect to the substituents around $C(6)$. The $O$ atoms are arranged tetrahedrally around $S$ but the average $\mathrm{S}-\mathrm{O}$ distance of $1.46 \AA$ indicates the existence of significant $\pi$-bond character in these bonds (Cruickshank, 1961). Consistent with this interpretation are the observations that all $\mathrm{O}-\mathrm{S}-\mathrm{O}$ bond angles are somewhat larger and all $\mathrm{C}-\mathrm{S}-\mathrm{O}$ angles are somewhat smaller than the tetrahedral angle of $109.5^{\circ}$. A similar phenomenon occurs in 2-amino-1-methylpyrimidinium 6-sulfonate (Pitman, Shefter \& Ziser, 1970) and other sulfonate structures (Hall \& Maslen, 1967).

The crystal may be considered to consist of sheets which are two anions thick and stacked parallel to the $b c$ plane. Each sheet occupies the space between $x=-\frac{1}{2}$ and $+\frac{1}{2}$. The two surfaces of these sheets are lined with sulfonate groups. The interface between these sheets,
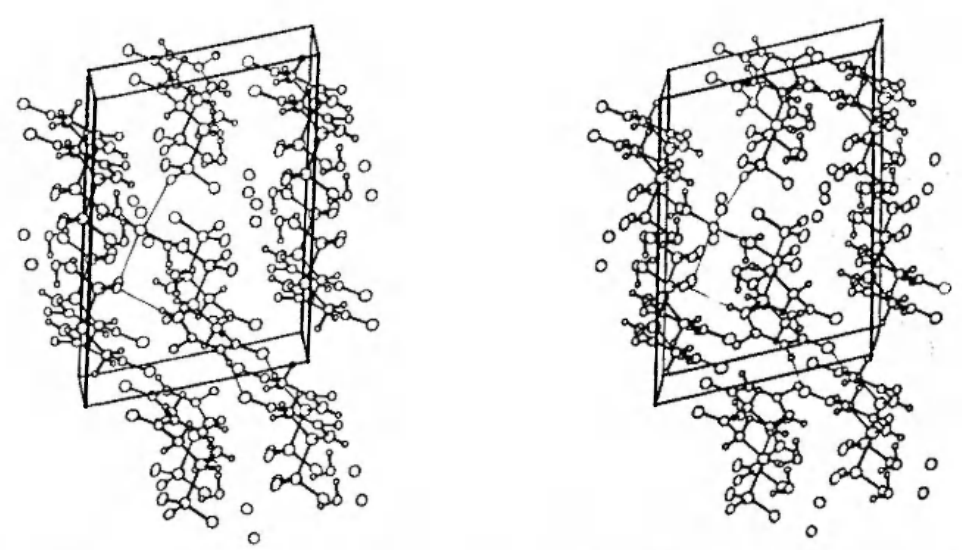

Fig. 4. Packing diagram. The $a$ axis runs nearly vertically up, the $b$ axis runs into the page, and the $c$ axis runs horizontally across. 
Table 4. Hydrogen-bond parameters

$\begin{array}{lccc}\quad X-\mathrm{H} \cdots Y & X \cdots Y(\mathrm{~A}) & \mathrm{H} \cdots Y(\dot{\mathrm{A}}) & \angle X-\mathrm{H} \cdots Y\left(^{\circ}\right) \\ \mathrm{N}(1)-\mathrm{H}(1) \cdots \mathrm{O}(1)^{\mathrm{i}} & 2.988(2) & 2.23(3) & 173(3) \\ \mathrm{N}(3)-\mathrm{H}(3) \cdots \mathrm{O}(4)^{\mathrm{il}} & 2.997(2) & 2.09(4) & 172(3) \\ \mathrm{O}(w)-\mathrm{H}(w, 1) \cdots \mathrm{S}(1) & 3.218(2) & 2.41(4) & 172(4) \\ \mathrm{O}(w)-\mathrm{H}(w, 2) \cdots \mathrm{O}(1)^{\mathrm{\prime \prime \prime}} & 3.125(2) & 2.59(4) & 130(4) \\ \mathrm{O}(w)-\mathrm{H}(w, 2) \cdots \mathrm{O}(2)^{\mathrm{iv}} & 3 \cdot 104(2) & 2.54(4) & 134(3)\end{array}$

Symmetry code for superscripts

$$
\begin{array}{ll}
\text { None } x, 1, z & \text { (iii) } x, 1+y, z \\
\text { (i) } x, \frac{1}{2}-y, \frac{1}{2}+z & \text { (iv) } 1-x, 1-y,-z \\
\text { (ii) }-x, \frac{1}{2}+y,\left(\frac{1}{2}-z\right)-1 &
\end{array}
$$

occurring at $x=\frac{1}{2}$, is largely hydrophilic and is where the $\mathrm{Na}$ ion and the water molecule are found. The $\mathrm{Na}$ atom is nearly on the crystallographic 2, screw axis and is surrounded by six $\mathrm{O}$ atoms in an octahedral array, with $\mathrm{O}-\mathrm{Na}-\mathrm{O}$ angles ranging from 82.5 to $99.4^{\circ}$ (Table 3 ). The equatorial plane of this octahedron is made by four sulfonate $\mathrm{O}$ atoms. The axial positions are occupied by water $\mathrm{O}$ atoms. One $\mathrm{H}$ of this water molecule is involved in a hydrogen bond with $S(1)$ (Table 4). The other appears to be involved in a bifurcated hydrogen bond, being close to both $O(1)$ of one DHTUS and $\mathrm{O}(2)$ of another (Table 4).

Each sheet, in turn, may be considered to be made of long chains. These chains run parallel to $b$ and possess crystallographic 2 , symmetry at $x=0, z=\frac{3}{1}$. The
DHTUS anions in a given chain are connected to or another by a strong hydrogen bond between $N(3)$ one anion and $\mathrm{O}(4)$ of its neighbor (Table 4 Neighboring chains in each sheet are related to on another by crystallographic $c$-glide symmetry $(0$ equivalently, by crystallographic center of inversio symmetry). There are numerous van der Waal interactions between chains, but also there is one stron hydrogen bond per anion connecting these chains. Thi hydrogen bond occurs near the surface of the shee between $\mathrm{N}(1)$ of one DHTUS and $\mathrm{O}(1)$ of another.

This work was supported in part by NIH Researcl Grant No. GM 18348 to Ian H. Pitman and T Higuchi.

\section{References}

Cruickshank, D. W. J. (1961). J. Chem. Soc. pp. 54865504.

Hall, S. R. \& Maslen, E. N. (1967). Acta Cryst. 22, 216228.

KoJic-Prodic, B., Ruzić-Torö, Z. \& Coffou, E. (1976). Acta Cryst. B32, 1099-1102.

Pitman, I. H., Shefter, E. \& Ziser, M. (1970). J. Am. Chem. Soc. 92, 3413-3417.

Seccombe, R. C., Lee, B. \& Henry, G. M. (1975). Inorg. Chem. 14, 1147-1153.

Shapiro, R., Servis, R. E. \& Welcher, M. (1970). J. Am. Chem. Soc. 92, 422-424.

Acta Cryst. (1978). B34, 930-932

\title{
Calcium Di(hydrogen maleate) Pentahydrate
}

\author{
By BENNETT HSU AND E. O. SCHLEMPER \\ Department of Chemistry, University of Missouri-Columbia, Columbia, Missouri 65201, USA
}

(Received 7 June 1977; accepled 1 November 1977)

\begin{abstract}
Ca}\left(\mathrm{C}_{4} \mathrm{H}_{3} \mathrm{O}_{4}\right)_{2} .5 \mathrm{H}_{2} \mathrm{O}$, orthorhombic, Pnam, $a=11.737$ (2), $b=6.477$ (1), $c=19.593$ (2) $\AA, Z=4$, $D_{m}=1.590, D_{c}=1.586 \mathrm{~g} \mathrm{~cm}^{-3}, \mu=1.40 \mathrm{~cm}^{-1}$, final $R\left(F^{2}\right)$ of 0.060 . Ca is seven coordinate with distorted monocapped trigonal prismatic geometry $(\mathrm{Ca}-\mathrm{O}$ ranges from 2.359 to $2.469 \mathrm{~A}$ ). The hydrogen maleate ion is coordinated to $\mathrm{Ca}$ through one $\mathrm{O}$ and possesses a short intramolecular $\mathrm{O} \cdots \mathrm{O}$ hydrogen bond $10 \cdots \mathrm{O}$ $2.426(1), \mathrm{O}-\mathrm{H} 1.13$ (3) and 1.31 (3) Al.
\end{abstract}

Introduction. The title compound was prepared by titrating a saturated aqueous solution of maleic acid with calcium nyaroxide to $\mathrm{pH}=3.95$. Solvent was then removed hy slow evaporation at room temperature to produce srystals suitable for diffraction studies. Pre cession photographs gave the systematic absences $0 k$ l, $k+l=2 n+1$, and $h 0 l, h=2 n+1$, which indicated that the space group was either Pnam or Pna2. The former was indicated by statistical examination of the distribution of $E$ values and was confirmed by the structure refinement. Any deviation from Pnam would be necessarily small because of the very successful refinement in Pnam. A crystal $(0.7 \times 0.6 \times 0.3 \mathrm{~mm})$ was mounted on a programmed Picker four-circle 